\title{
Cuidado colaborativo entre os Núcleos de Apoio à Saúde da Família e as equipes apoiadas
}

\section{| ${ }^{1}$ José Patrício Bispo Júnior, ${ }^{2}$ Diane Costa Moreira |}

Resumo: O cuidado colaborativo é apresentado como estratégia para ampliar a resolutividade na Atenção Primária à Saúde. Esse estudo analisa o cuidado colaborativo exercido entre os Núcleos de Apoio à Saúde da Família e as equipes de referência com base no Apoio Matricial. Pesquisa qualitativa desenvolvida em seis municípios da Bahia. Foram realizadas entrevistas com 43 profissionais dos núcleos de apoio e 40 das Equipes de Saúde da Família. Foi utilizada como matriz analítica o modelo da colaboração interprofissional, composto pelas dimensôes: Compreensão; Internalização; Governança; e Formalização. Nas quatro dimensôes, evidenciaramse dificuldades para a colaboração interprofissional. O trabalho colaborativo e a metodologia do Apoio Matricial são incompreendidas por ambas as equipes. Demonstrou-se existir tensionamentos sobre a função do matriciamento, com polarização entre as atividades coletivas e individuais. As gestôes municipais não dão a direcionalidade adequada à prática colaborativa. Condiçôes estruturais, materiais e formativas constituem-se em limitadores do Apoio Matricial. O trabalho entre os núcleos de apoio e as equipes apoiadas demonstra-se fragmentado e com baixa coesão necessária à atividade colaborativa.

> Palavras-chave: Atenção Primária à Saúde; Saúde da Família; relações interprofissionais; profissionais de apoio aos cuidados de saúde; Sistema Único de Saúde.
${ }^{1}$ Instituto Multidisciplinar em Saúde, Universidade Federal da Bahia. Vitória da Conquista-BA, Brasil (jpatricio@ufba.br). ORCID-0000-0003-4155-9612

${ }^{2}$ Mestrado em Saúde Coletiva, Universidade Federal da Bahia. Vitória da Conquista-BA, Brasil (dicmoreira@hotmail.com). ORCID- 0000-0003-1263-7677
Recebido em: 30/10/2017 Revisado em: 31/03/2018 Aprovado em: 24/04/2018 


\section{Introdução}

A complexidade dos problemas de saúde e a necessidade de tornar os sistemas mais responsivos às demandas dos cidadáos suscitam debates sobre as formas mais adequadas de organização do cuidado em saúde. Nesse contexto, a colaboração interprofissional é apresentada como forte estratégia para ampliar a efetividade dos serviços prestados e a resolutividade das açóes (MATUDA et al., 2013). Por meio da prática colaborativa interprofissional, novas configuraçôes de trabalho são estruturadas com o propósito de potencializar a interação entre os profissionais e a articulação do trabalho (WHO, 2010).

Por cuidado colaborativo entende-se o desenvolvimento do trabalho em saúde, a partir da interação entre profissionais de diferentes núcleos de saber, com foco prioritário nas necessidades dos usuários (MULVALE et al., 2016). Visa superar as tradicionais formas hierarquizadas de trabalho em equipe, procedimento centrado e pautado na mera aglutinação de práticas desarticuladas de diferentes especialidades (MATUDA et al., 2015). Tem como pressuposto o comprometimento da equipe com a resolutividade da atenção, a partir de constantes mecanismos de comunicação, integração e tomada de decisão em conjunto, com definiçôes de responsabilidades entre os componentes (MATUDA et al., 2015; MULLER-JUGE et al., 2014; NUÑO-SOLINÍS et al., 2013).

Tradicionalmente, os serviços de saúde organizam as práticas entre diferentes especialidades por meio de encaminhamentos e mecanismos de referência e contrarreferência entre os níveis de atenção. A fim de superar a burocratização do sistema e as dificuldades de acesso, observam-se em diversos países iniciativas de aproximação de profissionais especialistas com a Atenção Primária à Saúde (APS) (MULVALE et al., 2016). No entanto, o que os estudos demonstram é que apenas aglomerar novas especialidades na APS não assegura a qualificação do cuidado (OLIVEIRA; CAMPOS, 2015). Novas formas de organização do trabalho e da integração entre os profissionais são propostas com o intuito de reorientar e qualificar os modelos de atenção.

No Brasil, o cuidado colaborativo na APS ganha especial destaque a partir da criação dos Núcleos de Apoio à Saúde da Família (Nasf). Esses núcleos são compostos por profissionais de diferentes formaçôes e têm o propósito de ampliar a abrangência e a resolutividade da Estratégia Saúde da Família (ESF) (BRASIL, 
2012). O trabalho do Nasf fundamenta-se na metodologia do Apoio Matricial. O Apoio Matricial constitui-se numa proposta de mudança sobre como fazer o trabalho interprofissional de modo a superar os modelos hierarquizados de regulação entre profissionais de diferentes núcleos de saber (CAMPOS et al., 2014).

Nesse arranjo, os profissionais das áreas especializadas oferecem apoio às equipes de referência, responsáveis pelo cuidado cotidiano, na forma de retaguarda especializada e suporte técnico pedagógico (OLIVEIRA; CAMPOS, 2015). A forma de organização do trabalho se dá pela personalização das relações interprofissionais, com contato pessoal, discussão de casos e pactuação de atribuições entre os envolvidos. Com o Apoio Matricial, no lugar dos especialistas se incumbirem apenas por atividades e procedimentos, todos os profissionais envolvidos são responsáveis pelo caso, com discussão e pactuação de compromissos. Assim, busca-se construir a responsabilidade de pessoas por pessoas (CAMPOS et al., 2014). Trata-se de um modelo que almeja a democratização das relaçôes interprofissionais por meio da cogestáo e da maior implicação de especialistas e generalistas com o cuidado em saúde (CUNHA; CAMPOS, 2011).

O desenvolvimento do Apoio Matricial perpassa, precipuamente, pela integração e articulação entre os apoiadores e as equipes de referência. Constitui-se em inovadora metodologia de trabalho com o intuito de superar a lógica dos encaminhamentos que fragmenta o cuidado e compromete a responsabilização clínica e sanitária do trabalho interprofissional. A partir do Apoio Matricial, pretende-se assegurar, de modo dinâmico e interativo, a troca de conhecimentos que contribua para ampliar as possibilidades terapêuticas, com a realização da clínica ampliada e com o favorecimento da integração dialógica entre distintas profissóes da saúde (CUNHA; CAMPOS, 2011; CAMPOS et al., 2014).

Não obstante o caráter democratizante, abrangente e educativo da proposta do Apoio Matricial (CAMPOS et al., 2014), estudos demonstram dificuldades da interação entre os profissionais e da articulação do trabalho entre Nasf e Equipes de Saúde da Família (EqSF) (LANCMAN et al., 2013; SILVA et al., 2012; ELLERY et al., 2013).

Nesse sentido, o objetivo do presente estudo foi analisar o cuidado colaborativo exercido entre trabalhadores dos Nasfs e das EqSFs. Para isso, toma como referência o desenvolvimento do trabalho interprofissional com base no Apoio Matricial. 


\section{Métodos}

Estudo qualitativo em que o campo de pesquisa foi constituído por seis municípios da macrorregião de saúde do Sudoeste da Bahia, que possuíam Nasf em funcionamento há mais de um ano.

Os municípios participantes e algumas de suas características são: Vitória da Conquista, com população de 343.330 habitantes, cobertura de 42,6\% da Estratégia Saúde da Família e quatro equipes de Nasf; Guanambi, com população de 85.797 habitantes, cobertura de $76,9 \%$ da ESF e duas equipes de Nasf; Brumado, com população de 69.255 habitantes, cobertura da ESF de 69,98\% e três equipes de Nasf; Poçôes, com população de 48.729 habitantes, cobertura de ESF de 94,34\% e duas equipes de Nasf; Barra do Choça, com população de 38.853 habitantes, cobertura de $100 \%$ da ESF e uma equipe de Nasf; e Belo Campo, que possui população de 18.383 habitantes, cobertura de ESF de 95,48\% e uma equipe de Nasf(BRASIL, 2016).

Os dados foram obtidos por meio de entrevistas semiestruturadas com 43 profissionais do NASF e 40 das EqSFs, realizadas entre junho de 2014 e fevereiro de 2015. Entre os profissionais do Nasf, foram entrevistados 12 fisioterapeutas, nove nutricionistas, seis psicólogos, seis profissionais de educação física, cinco assistentes sociais, quatro farmacêuticos, um enfermeiro sanitarista. Entre as EqSFs, optou-se por entrevistar apenas médicos e enfermeiros, por essas categorias possuírem maior contato com o Nasf. Assim, foram entrevistados 27 enfermeiros e 13 médicos.

As entrevistas foram orientadas por roteiro que incluíam questóes sobre a articulação do trabalho entre Nasf e EqSF e a colaboração interprofissional na saúde da família. As mesmas foram realizadas pelos autores deste artigo e mais dois pesquisadores experientes e treinados. Como fonte complementar de dados, utilizaram-se os registros das observaçóes de campo.

Todas as entrevistas foram gravadas e transcritas. Como processo de validação, após a transcrição as mesmas eram ouvidas e checadas por outro membro da equipe de pesquisa. Para ordenação, sistematização e categorização dos dados, utilizou-se a técnica de categorização temática proposta por Gibbs (2009). Após a leitura exaustiva das entrevistas, foram definidos os códigos a ser utilizados no processo de análise. Cada código correspondeu a uma ideia temática ou núcleo de sentido. A codificação foi realizada a partir de novas leituras do material transcrito e a identificação das passagens do texto que se relacionavam com cada código. Os códigos e os respectivos 
excertos foram aglutinados, sinalizados e refinados de acordo com as dimensôes analíticas adotadas no estudo.

Foi utilizada como matriz analítica o 'Modelo de colaboração tetra dimensional' desenvolvido por D’Amour et al. (2008). Essa matriz tem sido aplicada para análise da colaboração interprofissional na APS (SCHADEWALDT et al., 2016) e em redes de cuidado integrado (NUÑO-SOLINÍS et al., 2013).

O modelo de D’Amour et al. (2008) é inspirado no conceito de ação coletiva da sociologia organizacional e baseia-se na premissa em que os profissionais trabalham juntos na perspectiva de oferecer melhores cuidados, mas ao mesmo tempo possuem os seus próprios interesses e querem manter um grau de autonomia e independência. Tal perspectiva demostra-se especialmente adequada à análise do trabalho de Apoio Matricial, que pressupóe limitar a fragmentação da atenção, consolidar a responsabilização clínica e valorizar o cuidado interdisciplinar (CASTRO; CAMPOS, 2016).

De acordo com o respectivo modelo, a açáo coletiva pode ser analisada por meio de quatro dimensôes (Figura 1). Duas das dimensôes envolvem componentes interacionais (Compreensão e Internalização) e duas envolvem componentes organizacionais (Governança e Formalização). Essas quatro dimensōes são operacionalizadas por meio de dez indicadores. A seguir, apresentam-se as quatro dimensôes e os respectivos indicadores do modelo analítico de D’Amour et al. (2008).

Figura 1. Modelo tetra dimensional da colaboração interprofissional. Adaptado de D’Amour et al. (2008)

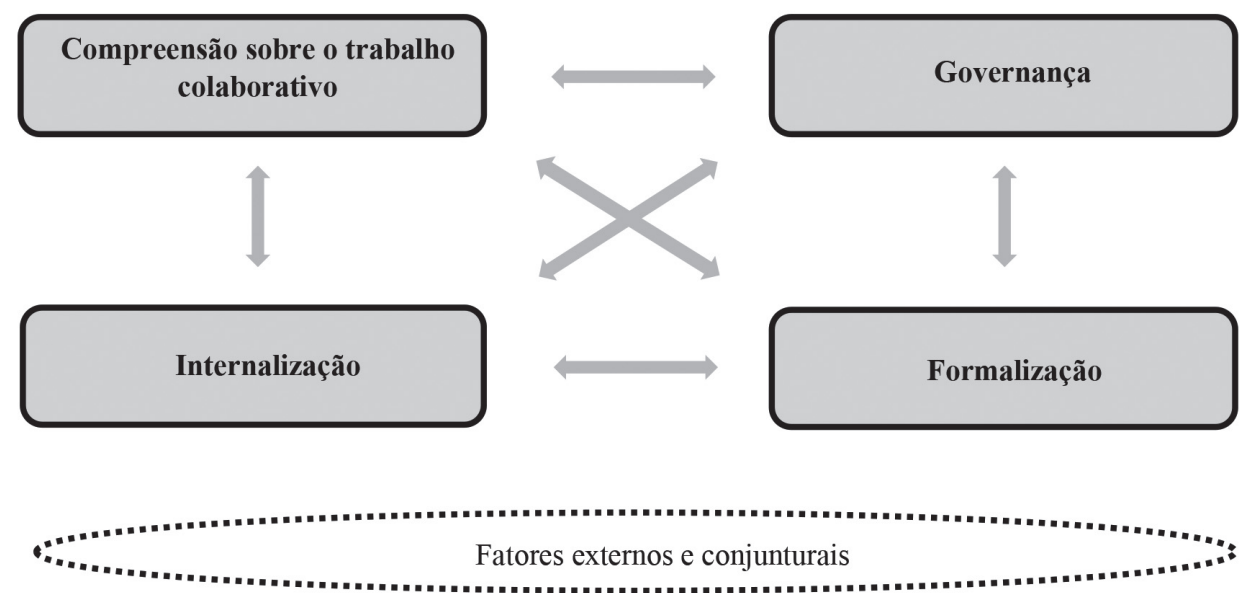


A dimensão Compreensão sobre o trabalho colaborativo refere-se à existência de objetivos comuns e a sua apropriação pelas equipes, o reconhecimento de motivaçóes diferentes, de múltiplos interesses, e a diversidade de definições e expectativas com relação à colaboração. É composta por dois indicadores: Objetivos comuns e Orientação ao usuário. O indicador Objetivos comuns envolve a existência de projetos terapêuticos compartilhados entre os profissionais, com particular referência à natureza explícita e consensual desses objetivos. Parte do princípio de que a definição de projetos terapêuticos (individuais, familiares ou comunitários) em comum constitui-se em instrumento potencializador do cuidado. A Orientação para o usuário tem como foco a valorização e priorização dos interesses dos usuários na prática do trabalho e na relação entre os profissionais.

A dimensão Internalização diz respeito à consciência sobre a importância do trabalho do outro e da interdependência entre os membros da equipe, considera os sentimentos de pertencimento e de confiança. É também constituída por dois indicadores. O Conhecimento mútuo refere-se à necessidade de conhecimento pessoal e profissional entre os envolvidos. Implica conhecer os núcleos disciplinares dos integrantes da equipe, a competência para o cuidado e o escopo da prática. $\mathrm{O}$ outro indicador é a Confiança, relacionada à segurança nas competências e habilidade do outro para assumir responsabilidades. Quando há desconhecimento e incerteza, os profissionais tendem a não compartilhar responsabilidades, constituindo-se em obstáculo para a colaboração.

A terceira dimensão, Governança, considera a existência de direcionalidade e apoio por parte da gestáo para o desenvolvimento do trabalho interprofissional colaborativo. Quatro indicadores integram essa dimensão: Diretrizes estratégicas, que dispóem sobre a direcionalidade empreendida por gestores para a promoção e implementação de processos e estruturas colaborativas; Gestão Coletiva, relacionada à presença de gestão participativa na equipe, com garantia que os membros possam ter suas opiniốes ouvidas e participar da tomada das decisôes sobre a gestão da clínica, os processos de trabalho e os fatores organizacionais; Apoio para o trabalho colaborativo, que pressupóe a necessidade de suporte institucional às novas práticas clínicas e sanitárias, nos componentes formativo, estrutural, das relaçôes e das condiçôes de trabalho; e Espaços de encontro, com garantia de espaço na agenda para discussôes de casos (individuais, familiares e comunitários) e construção de vínculos e compromissos entre os profissionais. 
Por fim, a Formalizaçáo esclarece expectativas e define responsabilidades, além de valorizar os mecanismos de comunicação entre os profissionais. Essa dimensão é formada pelos indicadores Pactuação de fluxos e responsabilidades, referente à definição de atribuições e ao esclarecimento do que se espera de cada profissional; e Comunicação, que diz respeito à existência e utilização adequada de mecanismos de troca de informação entre os profissionais. Pressupóe a prática e a valorização da comunicação com o uso de mecanismos formais (ex.: sistemas de informação) ou informais (ex.: encontros pessoais ou aplicativos de mensagens).

Importante destacar que as quatro dimensôes e os dez indicadores do modelo analítico estão interligados e afetam-se mutuamente(D’AMOUR et al., 2008). Assim, no processo de análise foi considerado a interdependência e que as características de uma dimensão interferem no comportamento de outra.

O estudo foi apreciado e aprovado pelo Comitê de Ética em Pesquisa do Instituto Multidisciplinar em Saúde da Universidade Federal da Bahia (IMS/UFBA), sob parecer 377.448/2013. Foram obedecidos todos os requisitos éticos estabelecidos pela Resolução 466/2012 do Conselho Nacional de Saúde. As entrevistas só foram realizadas após os esclarecimentos e a autorização do participante, com a assinatura do Termo de Consentimento Livre e Esclarecido em duas vias.

\section{Resultados}

$\mathrm{Na}$ tabela 1 são apresentadas as características sociodemográficas dos entrevistados. Observa-se maior quantidade de participantes mulheres em ambas as equipes (73,5\%). Os membros das EqSFs possuíam idade mais elevada, maior tempo de atuação na APS e maior tempo de atuação total. Sobre a qualificação profissional, aproximadamente $28 \%$ de cada grupo possuíam apenas graduação. Entre os pós-graduados, os membros das EqSFs apresentaram maior proporção na área da Saúde Coletiva e os participantes do Nasf, maior proporção em outras áreas.

Com base no modelo analítico utilizado, o cuidado colaborativo é uma prática ainda distante do trabalho entre Nasf e EqSF. Os resultados evidenciaram fragilidades na articulação e desenvolvimento do trabalho conjunto entre os dois grupos. Tanto os fatores relacionais como os organizacionais apresentaram relevantes interveniências. Os dados foram organizados e estão apresentados de acordo com as referidas dimensôes analíticas. Nas quatro dimensóes, evidenciaram-se dificuldades para o desenvolvimento da colaboraçáo interprofissional. 
Tabela 1. Perfil dos participantes segundo características sociodemográficas e profissionais. Bahia, 2015

\begin{tabular}{|c|c|c|c|c|c|c|}
\hline \multirow{2}{*}{ Variável } & \multicolumn{2}{|c|}{ Nasf } & \multicolumn{2}{|c|}{ EqSF } & \multicolumn{2}{|c|}{ Total } \\
\hline & $\mathrm{N}$ & $\%$ & $\mathrm{n}$ & $\%$ & $\mathrm{n}$ & $\%$ \\
\hline \multicolumn{7}{|l|}{ Sexo } \\
\hline Feminino & 30 & 69,8 & 31 & 77,5 & 61 & 73,5 \\
\hline Masculino & 13 & 30,2 & 9 & 22,5 & 22 & 26,5 \\
\hline \multicolumn{7}{|l|}{ Categoria Profissional Nasf } \\
\hline Fisioterapeuta & 12 & 27,9 & & & & \\
\hline Nutricionista & 9 & 20,9 & & & & \\
\hline Prof. de Educação Física & 6 & 14,0 & & & & \\
\hline Psicólogo & 6 & 14,0 & & & & \\
\hline Assistente Social & 5 & 11,6 & & & & \\
\hline Farmacêutico & 4 & 9,3 & & & & \\
\hline Enfermeiro Sanitarista & 1 & 2,3 & & & & \\
\hline \multicolumn{7}{|l|}{ Categoria Profissional EqSF } \\
\hline Enfermeiro (a) & & & 27 & 67,5 & & \\
\hline Médico (a) & & & 13 & 32,5 & & \\
\hline \multicolumn{7}{|l|}{ Idade } \\
\hline De 20 a 29 anos & 13 & 30,2 & 12 & 30 & 25 & 30,1 \\
\hline De 30 a 39 anos & 25 & 58,1 & 17 & 42,5 & 42 & 50,6 \\
\hline De 40 a 49 anos & 5 & 11,6 & 5 & 12,5 & 10 & 12,0 \\
\hline Maior que 50 anos & 0 & 0 & 6 & 15 & 6 & 7,2 \\
\hline \multicolumn{7}{|l|}{ Qualificação profissional } \\
\hline Apenas Graduação & 12 & 27,9 & 11 & 27,5 & 23 & 27,7 \\
\hline Pós-graduação na área de Saúde Coletiva & 14 & 32,6 & 17 & 42,5 & 31 & 37,3 \\
\hline Pós-graduação em outras áreas & 17 & 39,5 & 12 & 30 & 29 & 34,9 \\
\hline
\end{tabular}




\begin{tabular}{lcccccc}
\hline Variável & \multicolumn{2}{c}{ Nasf } & \multicolumn{2}{c}{ EqSF } & \multicolumn{2}{c}{ Total } \\
& $\mathrm{N}$ & $\%$ & $\mathrm{n}$ & $\%$ & $\mathrm{n}$ & $\%$ \\
\hline Tempo de atuaçáo no Nasf/ EqSF & & & & & & \\
$\quad$ Menor que 01 ano & 11 & 25,6 & 11 & 27,5 & 22 & 26,5 \\
De 01 a 03 anos & 14 & 32,6 & 10 & 25 & 24 & 28,9 \\
De 03 a 05 anos & 9 & 20,9 & 4 & 10 & 13 & 15,7 \\
Maior que cinco anos & 9 & 20,9 & 15 & 37,5 & 24 & 28,9 \\
Tempo total de atuação profissional & & & & & & \\
Menor que 01 ano & 2 & 4,7 & 2 & 5 & 4 & 4,8 \\
De 01 a 03 anos & 9 & 20,9 & 6 & 15 & 15 & 18,1 \\
De 03 a 05 anos & 12 & 27,9 & 6 & 15 & 18 & 21,7 \\
Maior que cinco anos & 20 & 46,5 & 26 & 65 & 46 & 55,4 \\
\hline
\end{tabular}

\section{Compreensão sobre o trabalho colaborativo}

$\mathrm{O}$ trabalho entre Nasf e EqSF demonstrou-se fragmentado e com baixa coesão necessária à atividade colaborativa. A interação entre equipes e a articulação de atividades são práticas pouco comuns. No cenário estudado, predomina uma forma de atuação do Nasf não só de maneira desarticulada, como em paralelo e isolada do trabalho das EqSFs.

Ambos os grupos desvelaram incompreensôes sobre o trabalho colaborativo, com trocas de acusaçôes recíprocas sobre tais incompreensôes. Como se a incompreensão do outro fosse o principal obstáculo para o desenvolvimento do trabalho articulado.

Os profissionais da equipe [de saúde da família] entendem o trabalho do Nasf como um serviço à parte. Não parte desse serviço da equipe, entendeu? Tá faltando maturidade deles para entender isso (NASF 12, Assistente Social).

O Nasf ainda não tem o seu papel dentro das equipes, a gente ainda não sabe pra quê que veio o Nasf. Nem o próprio Nasf sabe direito qual é o papel dele (EqSF 10, Enfermeiro).

Os indicadores dessa dimensão sinalizaram a não apropriação da colaboração como norteadora do trabalho entre os dois tipos de equipe. Quanto ao compartilhamento de objetivos comuns, os achados revelam que os profissionais não possuem perspectivas de trabalho compartilhado. Tampouco demostrou-se existir 
um processo de construção da colaboração entre os profissionais, com predomínio da lógica do trabalho individualizado.

Como base no modelo analítico, a compreensão da necessidade de definição de projetos terapêuticos singulares é elemento central para a organização do trabalho e o estabelecimento de responsabilidades. No entanto, os achados do estudo desvelam que os profissionais não percebem a necessidade de possuírem objetivos em comum e pactuarem responsabilidades, o que resulta em práticas assistenciais desconexas.

Então, é cada um no seu canto e não há uma integração. Não há uma avaliação daquela área que você tá trabalhando (Nasf 43, Psicólogo).

Constatou-se a frágil orientação ao usuário. Os interesses e precisóes dos usuários não se mostraram como fatores orientadores da prática profissional e como elementos capazes de favorecer o contato, a troca de experiências e a pactuação de responsabilidades entre os profissionais das duas equipes. Observou-se uma baixa orientação para o cuidado integral e a diminuta implicaçáo para garantia das premências assistenciais percebidas.

Se eu achar que precisa de um fisioterapeuta, eu coloco na folha de procedimento. Mas, depois não me é dada nenhuma satisfação. Porque não conseguiu o fisioterapeuta? Isso não volta pra mim (EqSF 17, Médico).

Os resultados evidenciaram a existência de práticas de trabalho burocratizada e de procedimento-centrada. Predomina a compreensão de que as responsabilidades profissionais se encerram em perceber a necessidade de atendimento por alguma especialidade e realizar o encaminhamento. A frágil orientação ao usuário expressase na diminuta implicaçáo para articular o cuidado com os profissionais da equipe mínima ou da equipe que presta apoio.

\section{Internalização}

Os resultados demonstram que a metodologia do Apoio Matricial não foi devidamente assimilada ou apresenta-se pouco convidativa aos profissionais. Constatou-se existir tensionamentos entre o que se configuraria na função de apoio às EqSFs. Para os profissionais do Nasf, o Apoio Matricial constitui-se quase que exclusivamente no desenvolvimento de atividades grupais e educativas. Por sua vez, profissionais das EqSFs expressam a necessidade de apoio na retaguarda especializada individual. 
Os profissionais das EqSFs, por não se sentirem apoiados nos atendimentos individualizados, tendem a desconsiderar o Nasf como pertencente à equipe de trabalho. Tal perspectiva abala os preceitos dos sentimentos de pertença e de interdependência inerentes à dimensão da Internalização.

Não se verificou desconhecimento ou desvalorização dos núcleos disciplinares específicos, a exemplo da fisioterapia, nutrição, psicologia ou farmácia. Pelo contrário, as EqSFs manifestaram consideráveis expectativas do atendimento dessas especialidades. Como essas expectativas não foram suficientemente atendidas e não se conhece ou não se valoriza outras competências do apoio, os profissionais passam a não requisitar ou a desvalorizar o trabalho do Nasf.

Muito difícil encaminhar usuários para o Nasf. Já encaminhei outras vezes, aí teve uma palestra dizendo que o Nasf náo funciona assim, funciona desse jeito e tal. Como não tive sucesso, aí não encaminhei mais (EqSF 02, Médico).

A análise do indicador Conhecimento mútuo revelou o incipiente domínio sobre a própria atuação e a atuação do outro na perspectiva do Apoio Matricial. Esse desconhecimento constituiu-se em dificultador por restringir as possibilidades de atuaçâo e o próprio escopo do trabalho colaborativo. Assim, o trabalho colaborativo com base no Apoio Matricial demonstrou não estar devidamente internalizado entre os profissionais das duas equipes, com o predomínio de facetas do que se constituiria a função de apoio.

Essa situação interfere no indicador confiança e no respeito entre as equipes. Foram percebidas situaçôes de descrédito e desconfiança dos médicos e enfermeiros sobre o trabalho do Nasf. Por sua vez, os profissionais do Nasf sentem-se desrespeitados e subutilizados no desempenho de suas atribuiçóes.

Eu considero o papel do Nasf muito importante, só não funciona (EqSF 22, Médico).

O que incomoda é justamente essas questóes, que, às vezes, a gente não tem respeito de outro profissional colega da gente, né? (Nasf 34, Nutricionista).

Tais situaçóes evidenciam uma clara divisão entre o tipo de apoio desejado pelas EqSFs e o que é pensado e disponibilizado como apoio pelos profissionais do Nasf. $\mathrm{O}$ hiato gerado abala a consciência de interdependência mútua e constitui-se em impeditivo para o desenvolvimento do trabalho colaborativo. 


\section{Governança}

Os municípios estudados são caracterizados por frágeis atributos de Governança na promoção do Apoio Matricial e do trabalho colaborativo na APS. Não obstante a implementação do Nasf, os resultados evidenciaram que as gestóes municipais não têm sido capazes de dar direcionalidade e apoio à prática colaborativa, o que interfere negativamente no trabalho do Nasf e no cuidado a ser desenvolvido.

Tudo é secundário quando é para o Nasf. Como é que a gente vai mostrar pra comunidade a importância que se tem, se a [gestão da] saúde não vê com esses olhos? (NASF 30, Psicólogo).

Foi evidenciado débil estabelecimento de Diretrizes Estratégicas pelas gestóes municipais para o desenvolvimento da colaboração. Os profissionais desenvolvem suas atividades sem que haja orientaçáo ou estabelecimento de rotinas e atividades que promovam a atuaçáo colaborativa entre as equipes.

A frágil direcionalidade também torna vulnerável a possibilidade da Gestão Coletiva. Os profissionais não se percebem pertencentes a um projeto em comum e não existem mecanismos claros de compartilhamento de responsabilidades entre as equipes. Assim, o planejamento compartilhado e a pactuação de atribuiçóes demonstram não serem práticas rotineiras no cenário estudado.

Não junta o Nasf com as equipes da saúde da família para planejar. Geralmente, eles têm o planejamento deles lá e a gente faz o nosso cá (Nasf 40, Psicólogo).

Também foram desveladas vulnerabilidades no indicador Apoio para o trabalho colaborativo. Evidenciaram-se fragilidades nas condiçōes estruturais, materiais e formativas necessárias ao desenvolvimento da colaboração entre equipes. Problemas relacionados ao espaço físico das unidades, carências de materiais e equipamentos e dificuldades de transporte comprometem o trabalho do Nasf e a articulação de atividades.

Outro empecilho que denota ausência de apoio e fragilidade das condiçôes de trabalho é o elevado número de EqSFs por Nasf. Verificou-se variação de sete a onze EqSFs por Nasf. Tal condição pressupóe elevado número de profissionais das EqSFs para que o Nasf se vincule e desenvolva o trabalho articulado.

A primeira dificuldade para o trabalho do Nasf é a demanda muito alta de equipes. [...]

Então, às vezes as nossas atividades são muito pontuais, não deveriam ser pontuais, deveriam ser mais vinculadas às equipes (Nasf 22, Prof. Educ. Física). 
Também foi evidenciada a inexistência de Espaços de Encontro institucionalizados para discussão de casos e coordenação da clínica. Entre os profissionais no Nasf, foi percebida a realização de reunióes periódicas. No entanto, não se demonstrou a cultura de discussão de casos, tampouco momentos protegidos na agenda das duas equipes para construção e ajuste de projetos terapêuticos compartilhados.

\section{Formalização}

A análise da quarta dimensão apresentou débeis mecanismos de Formalização de responsabilidades e pactuação de atividades. Formalização e pactuação pressupóem o trabalho devidamente articulado entre as equipes e o compartilhamento de responsabilidades entre os integrantes, o que náo foi constatado no estudo.

As definições de responsabilidades de cada equipe e quais as relativas à atuação conjunta não estão claramente estabelecidas. Tal situação implica potenciais vulnerabilidades do cuidado prestado. Alguns membros das EqSFs demonstraram que o desenvolvimento das atividades não é pensado para atuação conjunta com o Nasf.

A nossa atuação da equipe de saúde da família, ela não é muito ligada nessa preocupação de vamos articular junto com o Nasf, não (EqSF 13, Enfermeiro).

Por fim, os mecanismos de Comunicação demonstraram-se débeis, tanto em seus aspectos formais como informais. Não se constatou a institucionalização de mecanismos oficiais de comunicação entre as equipes para encaminhamento de casos ou solicitaçóes de apoio.

A gente não tem um formulário, por exemplo, de encaminhamento. Então, acho que dificulta as definições mesmo dos critérios, a gente não tem. A gente não tem nada que defina como é que deve ser feito esse fluxo (Nasf 41, Farmacêutico).

Da mesma forma, as práticas informais de comunicação provaram não ser efetivas. Foi evidenciada frágil comunicação informal para troca de informaçóes e discussóes de casos. Processos comunicacionais inadequados potencializam as dificuldades de esclarecimentos e pactuação de responsabilidades entre os profissionais e as equipes. Além do mais, a gestão do caso pressupóe troca de informaçôes diante de novos contextos ou situaçôes imprevistas. Nessas situações, a comunicação dinâmica e ágil favorece o apoio mútuo entre os profissionais e melhor articulação do cuidado tanto para o desenvolvimento das açóes pactuadas como para a resolução de problemas inesperados. 


\section{Discussão}

O trabalho em equipe na Estratégia Saúde da Família apresenta consideráveis desafios no que tange à integração profissional e articulação de açôes (SILVA et al., 2016; SANTOS et al., 2015). Com a implantação do Nasf, o debate sobre a interprofissionalidade ganha outros contornos. Primeiramente, pela própria dinâmica do trabalho, pois não se trata da atividade interprofissional entre os membros de uma mesma equipe. É o trabalho de uma equipe que presta apoio a outra. Isso demanda a necessidade de interação interna de cada equipe e a interação entre as equipes. Em segundo lugar, pela metodologia de trabalho fundamentada no Apoio Matricial. O Nasf não agrega apenas novas especialidades na atenção primária, mas, sobretudo, novas formas de atuação e organização do trabalho.

Nesse sentido, o uso do modelo tetradimensional de D’Amour et al. (2008) constituiu-se numa importante ferramenta metodológica para análise do complexo trabalho entre Nasf e EqSF. Embora o Apoio Matricial possua especificidade própria e avance também como possibilidade de arranjo organizacional dos serviços de saúde (CUNHA; CAMPOS, 2011), notam-se importantes similaridades entre os pressupostos de Apoio Matricial e as dimensóes e indicadores do modelo tetradimensional da colaboração interprofissional.

De acordo com a perspectiva de Oliveira e Campos (2015), o matriciamento fundamenta-se a partir de três diretrizes: o apoio, a cogestão e a corresponsabilização. Assim, as relaçóes interprofissionais devem transcender a lógica da mera divisão de tarefas, da hierarquização com sobrevalorização do especialista e do não compromisso com o cuidado integral. Propósitos que são também vislumbrados nas dimensôes da colaboração interprofissional.

Com base no modelo, os resultados do estudo demonstraram que a colaboraçáo entre Nasf e EqSF é permeada de fragilidades nas quatro dimensōes.

$\mathrm{Na}$ dimensão Compreensão sobre o trabalho colaborativo, observou-se que na prática cotidiana Nasf e EqSF não orientam o trabalho a partir de projetos terapêuticos em comum e construídos coletivamente. As incompreensôes sobre o desenvolvimento da colaboração interprofissional baseada no matriciamento resultam no isolamento do Nasf e na fragmentação do trabalho. A frágil interação e o baixo grau de articulação entre as duas equipes foram também observados em Fortaleza (RIBEIRO et al., 2015) 
e em São Paulo (LANCMAN et al., 2014), com manifestações de sentimento de impotência e de subutilização entre os profissionais do Nasf.

$\mathrm{O}$ indicador Orientação ao usuário apresentou fragilidades na coordenação assistencial e na longitudinalidade do cuidado. Os resultados indicaram inexistir um processo de acompanhamento do usuário a partir de suas necessidades. Tal perspectiva se constitui como inadequada ao trabalho do Nasf, visto o objetivo de contribuir para superar a fragmentação e a desresponsabilização assistencial (BRASIL, 2012). Espera-se que com a incorporação do Nasf ocorra o fortalecimento do compromisso com o território e o estabelecimento de relação orgânica e regular entre as equipes (CUNHA; CAMPOS, 2011).

A análise da dimensão Internalização revelou existir desconhecimento e resistências à metodologia do Apoio Matricial. Por se constituir em arranjo organizacional que visa horizontalizar e personalizar as relações interprofissionais, o Apoio Matricial tem enfrentando diversas objeçôes (MATUDA et al., 2015; BARROS et al., 2015; KLEIN; D’OLIVEIRA, 2017). A função de apoio demanda o conhecimento recíproco das açôes a ser desempenhadas pelos profissionais das duas equipes. Quando isso não está totalmente esclarecido, esvazia-se a expectativa do apoio e abala-se a confiança no trabalho do outro.

O tensionamento entre atividades individuais e coletivas demonstra ser uma questão de grande importância para a articulação do trabalho entre EqSF e Nasf. Nesse sentido, a visão dicotomizada entre NASF e EqSF sobre atividades coletivas e atendimento individual evidencia limitaçôes na internalização da função de apoio, o que afeta o sentimento de pertencimento e a confiança entre as equipes.

Os documentos normativos (BRASIL, 2012; 2014) e importantes produçóes sobre o trabalho do Nasf (CUNHA; CAMPOS, 2011; LANCMAN et al., 2013; SILVA et al., 2012; SOUZA; CALVO, 2016) destacam que este deve se voltar precipuamente para atividades coletivas. No entanto, Tesser (2017) chama a atenção sobre a subvalorização do cuidado especializado por parte dos profissionais de apoio e apresenta críticas à ênfase de papéis generalistas por parte dos especialistas. Para o autor, o afastamento do Nasf do cuidado especializado gera um apartheid assistencial, em que as EqSFs suportam sozinhas as demandas por atendimento clínico e os profissionais do Nasf mantêm-se protegidos dessas pressôes por manter o foco nas açóes grupais. 
Sobre a Governança, foram indicadas fragilidades das gestôes municipais em impelir direcionalidade e conceder o suporte necessário à colaboração. Importante refletir que o desenvolvimento do Apoio Matricial não se dará unicamente a partir da criaçấo do Nasf ou dos esforços individuais dos membros das equipes (MATUDA et al., 2015). Mas, sobretudo, com a institucionalização do apoio como diretriz estratégica de organização da atenção primária. Nesse sentido, cabe às gestôes municipais instituir e garantir as condiçôes necessárias para a consolidação do Apoio Matricial.

Quanto ao indicador Apoio para o trabalho, o estudo evidenciou vulnerabilidade de condições estruturais imprescindíveis à colaboração. As dificuldades de materiais e equipamentos, inadequação dos espaços físicos e grande número de EqSF por Nasf comprometem o trabalho junto às equipes apoiadas. Isso não é uma exclusividade do cenário estudado, questôes estruturais mostram-se como obstáculos também em outras realidades (LANCMAN et al., 2013; RIBEIRO et al., 2015; MARTINEZ et al., 2016).

Ainda sobre a Governança, a inexistência de espaços institucionalizados de encontro mostrou-se como indicativo de fragilidade para o Apoio Matricial. O principal dispositivo do Apoio Matricial é o compartilhamento de responsabilidades e a deliberação conjunta sobre projeto terapêutico a ser desenvolvido (OLIVEIRA; CAMPOS, 2015; CAMPOS et al., 2014). Dessa forma, o espaço de encontro é condição sine qua non para a função de apoio. O exemplo de Campinas demonstra a importância do encontro entre as equipes para a discussão de casos, construção de Projeto Terapêutico Singular e definiçáo de intervençôes em conjunto (CASTRO et al., 2016).

No que diz respeito à dimensão Formalização, os resultados revelaram o quão frágeis são os mecanismos de comunicação e de pactuação de responsabilidades. A comunicação é elemento essencial à colaboração interprofissional. Para Foy et al. (2010) constitui-se como principal elemento para a efetividade do cuidado articulado entre generalistas e especialistas no âmbito da APS.

Dentre os pressupostos do Apoio Matricial, encontram-se a personalização das relaçóes profissionais e a definição clara de responsabilidades pelo caso (OLIVEIRA; CAMPOS, 2015). Nesse sentido, os achados do presente estudo demonstram que a fragilidade nos mecanismos de comunicação e pactuação constitui-se em importante entrave para o desenvolvimento da metodologia de apoio. 


\section{Considerações finais}

Diante dos resultados encontrados, cabe refletir que a colaboração interprofissional é um arranjo complexo, permeado por interesses heterogêneos e compreensôes divergentes. Tratando-se da colaboração por meio do Apoio Matricial, tal realidade se torna ainda mais complexa diante dos mecanismos de gestão horizontal do cuidado, com a superação da hierarquia entre as profissōes.

As limitaçóes do estudo referem-se à própria complexidade do objeto analisado. Náo é possível capturar todos os fatores que influenciam na colaboração, principalmente os fatores externos e conjunturais. San-Martin et al. (2005) destacam a existência de determinantes sistêmicos, como questóes sociais, culturais e do sistema educacional, com grande poder de influência sobre a prática colaborativa.

Como síntese, o estudo apresentou fragilidades nos componentes interacionais e organizacionais que precisam ser superados no intuito de potencializar a colaboração interprofissional e ampliar a resolutividade do cuidado na APS. A criação do Nasf constitui-se em avanço em direção à qualificação do cuidado. No entanto, se faz premente a implicação da gestão municipal na adoção do Apoio Matricial como forma de organização do trabalho e na viabilização das condiçôes necessárias ao seu desenvolvimento. Também não se pode prescindir do comprometimento dos profissionais com as necessidades dos usuários e de estarem abertos a novos processos de trabalho colaborativos e horizontalizados. ${ }^{1}$

\section{Referências}

BARROS, J. O. et al. Estratégia do apoio matricial: a experiência de duas equipes do Núcleo de Apoio à Saúde da Família (NASF) da cidade de São Paulo, Brasil. Ciência \& Saúde Coletiva, v. 20, n. 9, p. 2847-2856, 2015.

BRASIL. Política Nacional de Atenção Básica. Brasília: Ministério da Saúde, 2012.

. Núcleo de Apoio à Saúde da Família . Brasília: Ministério da Saúde, 2014. (Cadernos da Atenção Básica, 39, v. 1.)

- Ministério da Saúde. Sala de Gestão Estratégica e Participativa-SAGE. Saúde mais perto de você 2016. Disponível em: <http:sage.saude.gov.br/\#>. Acesso em: 1 set. 2017.

CAMPOS, G. W. S. et al. A aplicação da metodologia Paideia no apoio institucional, no apoio matricial e na clínica ampliada. Interface - Comunicação, Saúde, Educação,v. 18, supl 1, p. 983 $995,2014$. 
CASTRO, C. P.; CAMPOS, G. W. S. Apoio Matricial como articulador das relaçóes interprofissionais entre serviços especializados e atenção primária à saúde. Physis - Revista de Saúde Coletiva, v. 26, n. 2, p. 455-481, 2016.

CASTRO, C. P.; OLIVEIRA, M. M.; CAMPOS, G. W. S. Apoio Matricial no SUS Campinas: análise da consolidação de uma prática interprofissional na rede de saúde. Ciência \& Saúde Coletiva, v. 21, n. 5, p. 1625-1636, 2016.

CUNHA, G. T.; CAMPOS, G. W. S. Apoio Matricial e Atenção Primária em Saúde. Saúde e Sociedade, v. 20, n. 4, p. 961-970, 2011.

D'AMOUR, D. et al. A model and typology of collaboration between professionals in healthcare organizations. BMC Health Services Research, v. 8, n. 188, 2008.

ELlERY, A. E. L.; PONTES, R. J. S.; LOIOLA, F. A. Campo comum de atuação dos profissionais da Estratégia Saúde da Família no Brasil: um cenário em construção. Physis Revista de Saúde Coletiva, v. 23, n. 2, p. 415-437, 2013.

FOY, R. et al. Meta-analysis: effect of interactive communication between collaborating primary care physicians and specialists. Annals of Internal Medicine, v. 152, n. 4, p. 247-258, 2010.

GIBBS, G. Análise de Dados Qualitativos. Porto Alegre: Artmed, 2009.

KLEIN, A. P.; D'OLIVEIRA, A. F. P. L. O "cabo de força" da assistência: concepção e prática de psicólogos sobre o Apoio Matricial no Núcleo de Apoio à Saúde da Família. Cadernos de Saúde Pública,v. 33, n. 1, e00158815, 2017.

LANCMAN, S. et al. Estudo do trabalho e do trabalhar no Núcleo de Apoio à Saúde da Família. Revista de Saúde Pública,v. 47, n. 5, p. 968-975, 2013.

MARTINEZ, J. F. N.; SILVA, M. S.; SILVA, A. M. O Núcleo de Apoio à Saúde da Família em Goiânia (GO): percepçóes dos profissionais e gestores. Saúde em Debate, v. 40, n. 110, p. 95-106, 2016.

MATUDA, C. G.; AGUIAR, D. M. L.; FRAZÃO, P. Cooperação interprofissional e a Reforma Sanitária no Brasil: implicaçóes para o modelo de atenção à saúde. Saúde e Sociedade, v. 22, n. 1, p. 173-186, 2013.

MATUDA, C. G. et al. Colaboração interprofissional na Estratégia Saúde da Família: implicaçôes para a produção do cuidado e a gestão do trabalho. Ciência \& Saúde Coletiva, v. 20, n. 8, p. 2511-2521, 2015.

MULLER-JUGE, V. et al. Interprofessional collaboration between residents and nurses in general internal medicine: a qualitative study on behaviours enhancing teamwork quality. PLOS One, v. 9, n. 4, 2014. 
MULVALE, G.; EMBRETT, M.; RAZAVI, S. D. 'Gearing Up' to improve interprofessional collaboration in primary care: a systematic review and conceptual framework. BMC Family Practice, v. 17, n. 83, 2016.

NUÑO-SOLINÍS, R. et al. Development of a questionnaire to assess interprofessional collaboration between two different care levels. International Journal of Integrated Care, v. $13,2013$.

OLIVEIRA, M. M.; CAMPOS, G. W. S. Apoios matricial e institucional: analisando suas construçôes. Ciência \& Saúde Coletiva, v. 20, n. 1, p. 229-238, 2015.

RIBEIRO, H. M. C. B. et al. Representaçóes sociais de profissionais de núcleos de apoio à saúde da família sobre interdisciplinaridade. Trabalho, Educação e Saúde, v. 13, supl 2, p. 97-115, 2015. SAN MARTÍN-RODRÍGUEZ, L. et al. The determinants of successful collaboration: a review of theoretical and empirical studies. Journal of Interprofessional Care, v. 19, supl. 1, p. 132-147, 2005.

SANTOS, A. F. et al. Apoio institucional e matricial e sua relação com o cuidado na atenção básica à saúde. Revista de Saúde Pública,v. 49, n. 54, 2015.

SCHADEWALDT, V. et al. Experiences of nurse practitioners and medical practitioners working in collaborative practice models in primary healthcare in Australia - a multiple case study using mixed methods. BMC Family Practice, v. 17, n. 99, 2016.

SILVA, A. T. C. et al. Núcleos de Apoio à Saúde da Família: desafios e potencialidades na visão dos profissionais da Atenção Primária do Município de São Paulo, Brasil. Cadernos de Saúde Pública, v. 28, n. 11, p. 2076-2084, 2012.

SILVA, M. C. et al. Adaptação transcultural e validação da escala de clima do trabalho em equipe. Revista de Saúde Pública, v. 50, n. 52, 2016.

SOUZA, T. T.; CALVO, M. C. M. Resultados esperados dos Núcleos de Apoio à Saúde da Família: revisão de literatura. Saúde e Sociedade, v. 25, n. 4, p. 976-987, 2016.

TESSER, C. D. Núcleos de Apoio à Saúde da Família, seus potenciais e entraves: uma interpretação a partir da atenção primária à saúde. Interface - Comunicação, Saúde, Educação, v. 21, n. 62, p. 565-78, 2017.

WORLD HEALTH ORGANIZATION. Framework for Action on Interprofessional Education \& Collaborative Practice. Geneva: WHO, 2010.

\section{Notas}

${ }^{1}$ J. P. Bispo Júnior contribuiu na concepção do estudo, coleta e interpretação dos dados, redação e revisão crítica do artigo e aprovação da versão final. D. C. Moreira contribuiu na coleta e interpretação dos dados, redação e revisão crítica do artigo e aprovação da versão final. 


\section{Abstract}

\section{Collaborative care among the Family Health Support Centers and the supported teams}

Collaborative care is presented as a strategy to increase resolutiveness in Primary Health Care. This study analyzes the collaborative care between the Family Health Support Centers and the reference teams based on the Matrix Support. Qualitative research developed in six municipalities of Bahia state, Brazil, with interviews conducted with 43 professionals from the support groups and 40 from the Family Health Teams. The model of the inter-professional collaboration was composed by the dimensions: Understanding; Internalization; Governance; and Formalization. In the four dimensions, there were difficulties for interprofessional collaboration. The collaborative work and the Matrix Support methodology are misunderstood by both teams. Tension exists on the function of matriciation, with polarization between collective and individual activities. Municipal management does not give adequate directivity to the collaborative practice. Structural, material and formative conditions are limits for the Matrix Support. The work between the support nuclei and the supported teams is fragmented and with low cohesion necessary for the collaborative activity.

> Keywords: Primary Health Care; Family Health; interprofessional relations; allied health personnel; Unified Health System. 